\title{
Effect of inlet air swirl on four stroke single cylinder diesel engine's performance
}

\author{
Dr. Hiregoudar Yerrennagoudaru ${ }^{1}$, Shivaprasad Desai ${ }^{2}$ \\ ${ }^{I}$ Professor and PG Co-coordinator (Thermal Power Engineering), Mechanical Engineering Department, \\ RYMEC Bellary, Karnataka, India \\ ${ }^{2}$ M.Tech (Thermal Power Engineering), Mechanical Engineering Department, RYMEC Bellary, Karnataka, \\ India
}

\begin{abstract}
Optimizing airflow performance during intake valve process is the main purpose for this project. Analyses were done in CFD simulation and experimental using a test rig single cylinder 4 stroke direct injection diesel engine. This analysis also reported and compared with both analyses where experimental result can meet a nearly required targeted limit due to some realistic condition.

Fabrication of intake valves also were made to do analysis on experimental based on the modify design. This being done after simulation analysis, modeling design was using to be fabricated and analyze the model on test rig machine to verify simulating result. This analysis could be used to increase thermal efficiency and maximizing usage of air fuel in combustion process, which reduce pollution to environment. Even though air flow have been optimized on its intake valve, but still intake system could be improve by considering other parts of engine such as intake manifold.
\end{abstract}

Keywords: Swirl, Turbulence, cfd analysis, thermal efficiency $H C$ and $C O$

\section{Introduction}

Due to heterogeneous combustion the thermal " $\eta$ " of C.I. Engine is less in spite of using a large excess air. Therefore thought of conducting the experiment to overcome the above problem of low thermal efficiency \& also to reduce levels of pollution. The thermal efficiency of the conventional C.I. Engine is low around $20 \%$ to $28 \%$ due to low rate of air swirl and improves the improper mixing of air and fuel. If the swirl is weak the products of combustion are not swept away fast from the surface of the burning drop plate. This will further suffocate burning of droplet.

Hence to optimize swirl, inlet valve with different shapes on its periphery can be made first and simulated through computational fluid dynamic. The software used for this project is starcem+. Results are compared for maximum swirl and turbulent kinetic energy and finally a physical model is prepared through some suitable materials and through machining.

Here three varieties of inlet valves are used,

1. Base model (The conventional inlet poppet valves)

2. Type-1 valve (Inlet valve with masks on its back)

3. Type-2 valve (Inlet valve with fins on its back)

Base model (conventional inlet poppet valves):

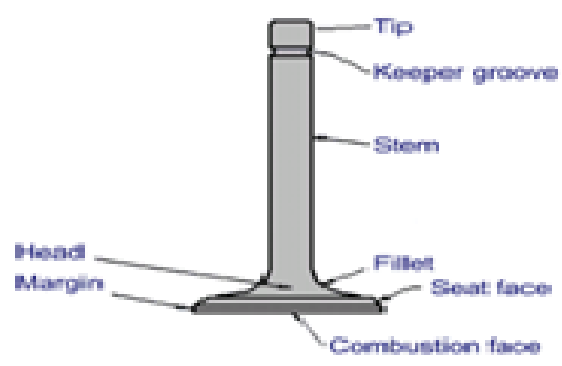

FIG1

The conventional inlet valve is as shown above, consisting of combustion face which is exposed to a very high temperatures during the process of combustion. Valve is having a delicate part called seating which should be very accurate enough in dimensions and finishing so that accurate locking and sealing enhances the whole engine performances. 
Type-1 inlet valve (valve with masks on its head):
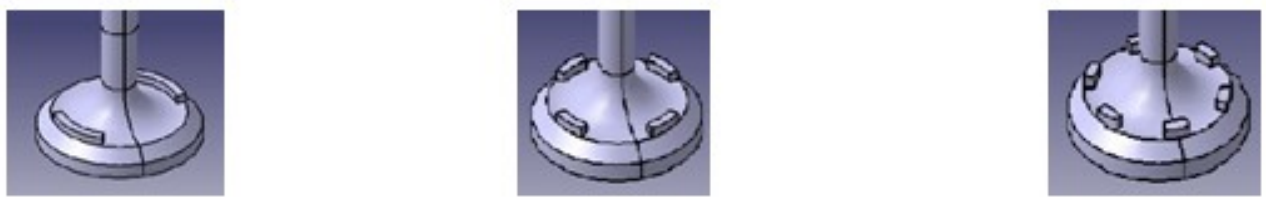

FIG-2 Type-1 inlet valves.

Masking is the process of building a small piece of metal on the valve head without disturbing the valve seating; the small pieces are called masks. Here for analysis we have used 2-masked valves, 4-masked valve and 6- masked valve, which are having the following dimensions:

Angle of mask: $120^{\circ}$

Width of mask: $2 \mathrm{~mm}$

Thickness of mask: $2 \mathrm{~mm}$

Outer dia of mask: $28 \mathrm{~mm}$

Inner dia of mask: $24 \mathrm{~mm}$

Hence these masks are split into 2,4 and 6 pieces angularly i.e., $120^{\circ} / 2=60^{\circ}$ masks in 2 pieces

$120^{\circ} / 4=30^{\circ}$ masks in 4 pieces

$120^{\circ} / 6=20^{\circ}$ masks in 6 numbers

Type-2 inlet valves (valve with extended fins on its head):
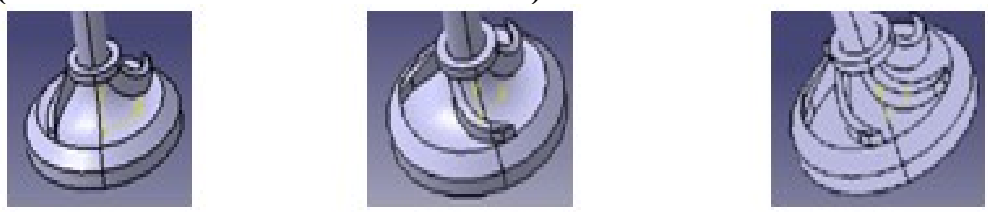

FIG-3 Type-2 inlet valves

In this type a small ring consisting fixed vanes are used as fins and are easily detachable from the valve body. The fins are equi- spaced on a circular orbit with varying numbers say two, three and five as shown in figure. The dimensions are: inner ring dia-7.8mm

Thickness of ring: $2 \mathrm{~mm}$

Width of ring: $2 \mathrm{~mm}$

Length of vane: $12 \mathrm{~mm}$

Width and thickness of vane: $2 \mathrm{~mm}$

Angle of vane: $45^{0}$ bent approximately down to adjust on valve head.

Simulation using cfd:

Simulation requires valve models, engine inlet manifold model, combustion chamber model, engine operating parameters. Discussion of each may become a very lengthy topics hence just explained through some neat sketches

Engine manifold:

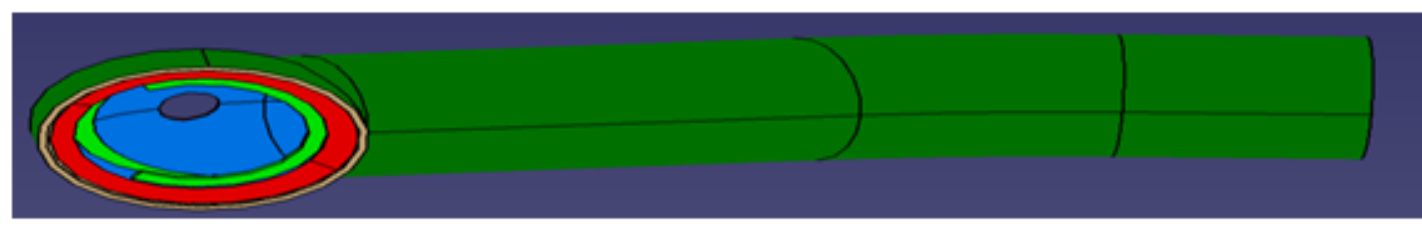

FIG-4 Intake Manifold

Engine combustion chamber (bowl-in-piston):

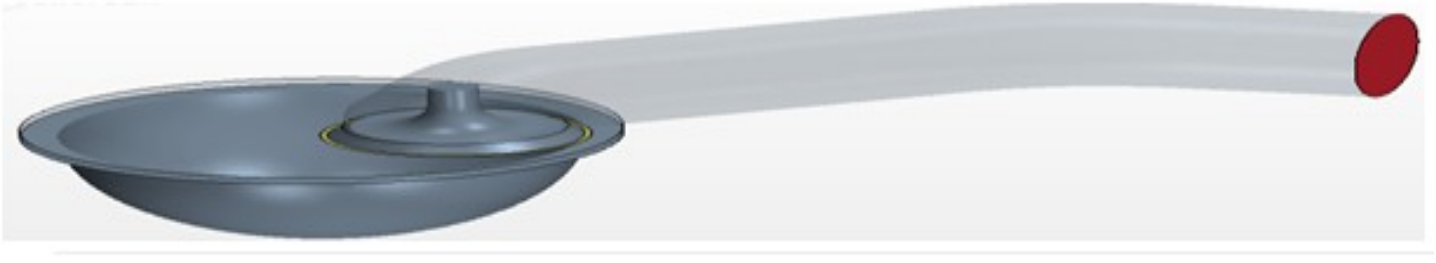




\section{Engine operating parameters:}

WATER COOLED, SINGLE CYLINDER, 4-STROKE DIESEL ENGINE SPECIFICATIONS:

$\mathrm{BHP}=5 \mathrm{HP}$

$=3.68 \mathrm{KW}$

Bore Diameter

$=80 \mathrm{~mm}$

Stroke length

$=110 \mathrm{~mm}$

Speed

$=1500 \mathrm{rpm}$

Brake drum Radius

$=147 \mathrm{~mm}$

C.V of Diesel

$=45,355 \mathrm{Kj} / \mathrm{Kg}$

Specific Gravity of diesel $\quad=0.8225 \mathrm{gms} / \mathrm{cc}$

Orifice dia

$=15 \mathrm{~mm}$

Brake Rope dia

$=15.9 \mathrm{~mm}$

Torque arm radius

$=0.2 \mathrm{mts}$

$=16.5: 1$

\section{Simulation By Using Cfd:}

Here valve lift is considered as major criterion for simulation.

Total valve lift $=12 \mathrm{~mm}$

This $12 \mathrm{~mm}$ is divided into 3 parts and called as

Low Lift (valve at $4 \mathrm{~mm}$ downward movement)

Medium lift (valve at $8 \mathrm{~mm}$ downward movement)

High lift (valve at $12 \mathrm{~mm}$ downward movement)

Hence CFD simulations were carried out for analyzing swirl, turbulence, velocity of inlet air and also pressure distribution inside the cylinder during suction stroke and are analyzed at different inlet valve lift positions in comparison with base model.

\section{Analysis of swirl by simulation:}

FIG-6 BASE MODEL:

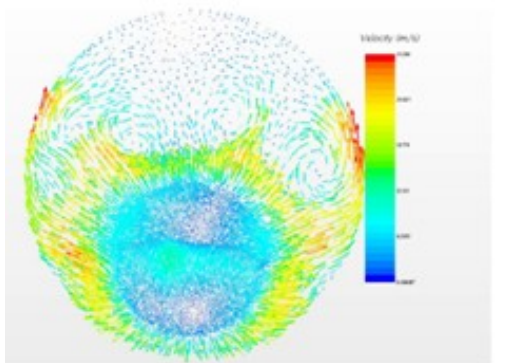

AT LOW LIFT

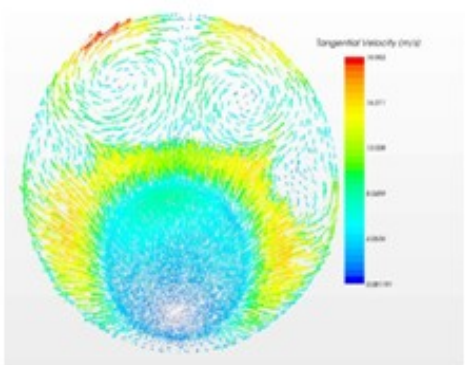

AT MEDIUM LIFT

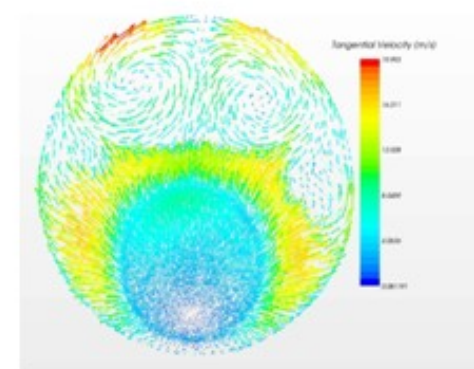

AT HIGH LIFT

The swirl intensity is very less at the medium and at high valve lifts. Compare this intensity with the following model; we can notice that which type of valve will give better swirl intensity

FIG-7 2 masked valve

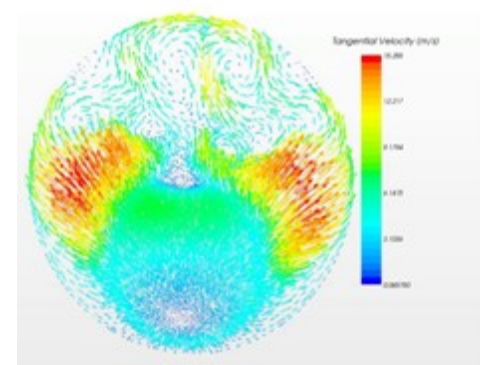

AT LOW LIFT

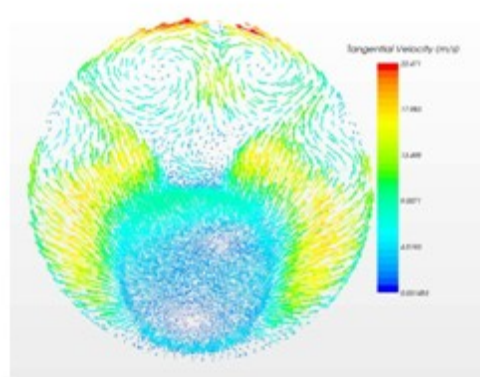

AT MEDIUM LIFT

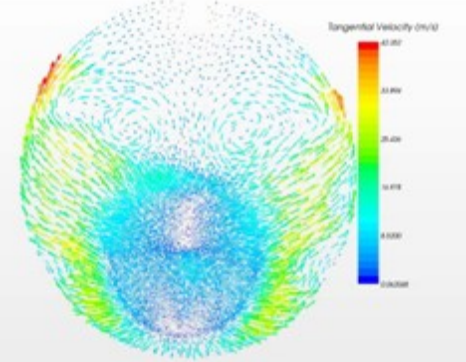

AT HIGH LIFT 
4 masked valve:

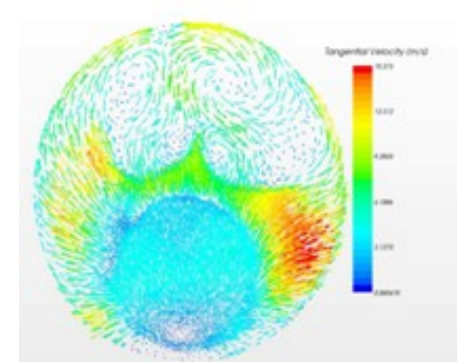

AT LOW LIFT

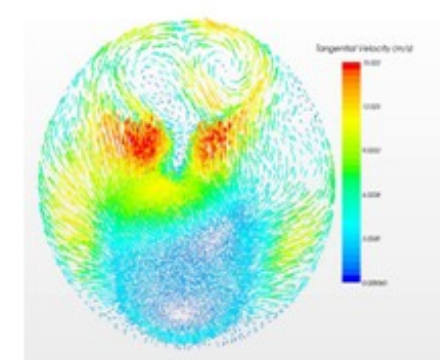

AT LOW LIFT

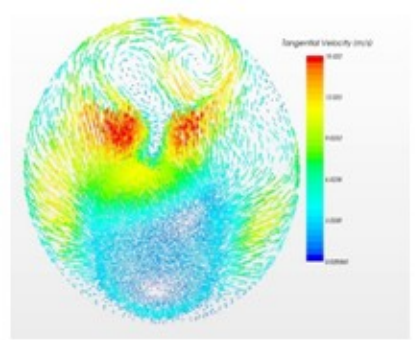

AT LOW LIFT

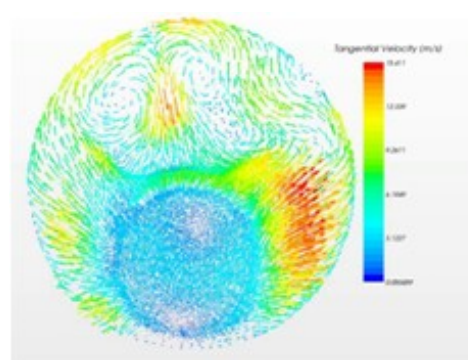

AT LOW LIFT

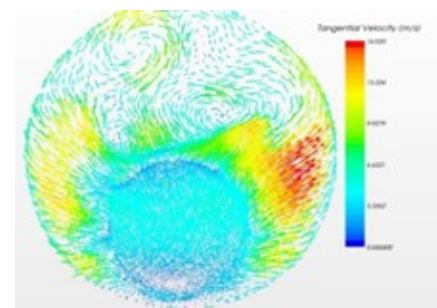

AT LOW LIFT

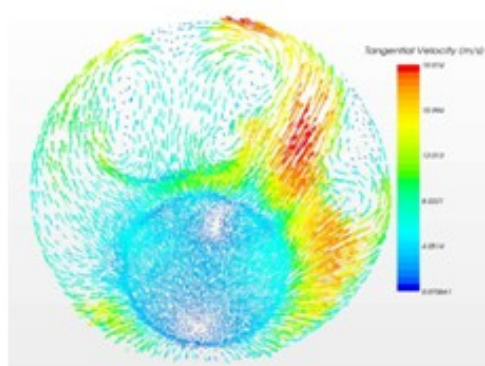

AT MEDIUM LIFT

6masked valve:

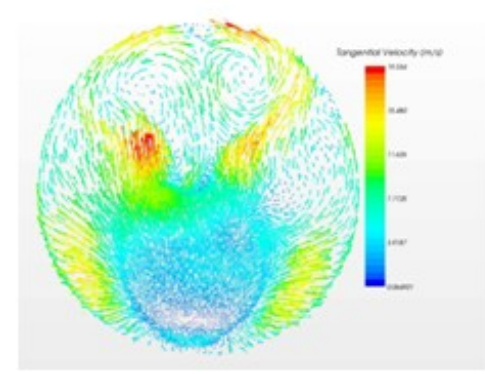

AT MEDIUM LIFT

2 finned valve:

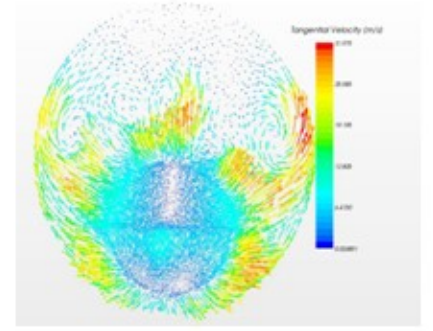

AT MEDIUM

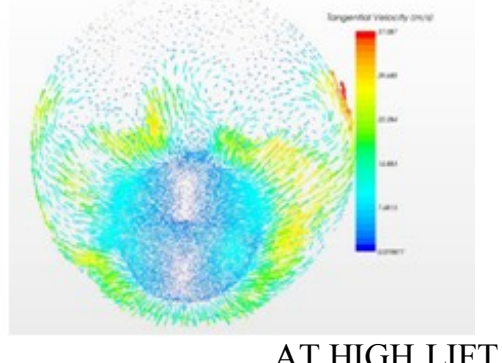

AT HIGH LIFT

3 finned valve

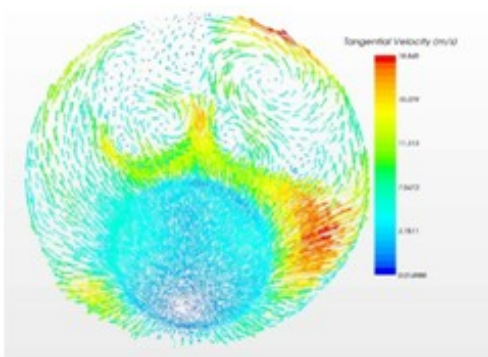

AT MEDIUM LIFT

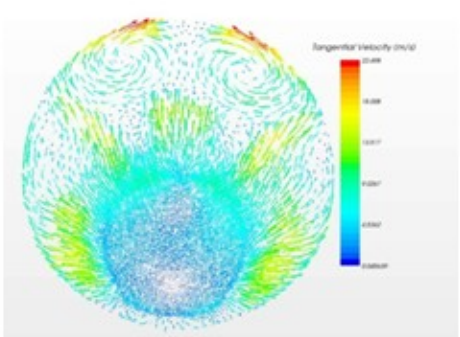

AT HIGH LIFT

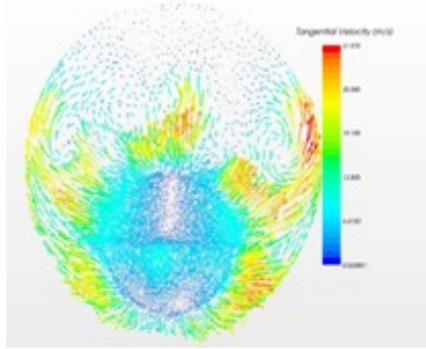

AT HIGH LIFT

\section{5 finned valve:}
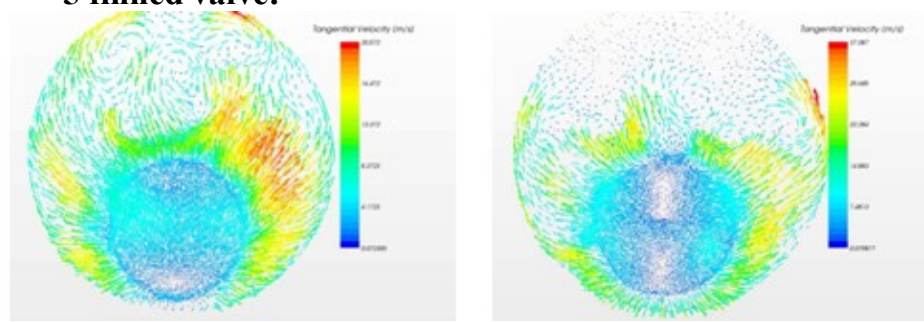

MEDIUM LIFT 
Hence a table of swirl ratios and turbulent kinetic energy can Give ideas to optimize the swirl through inlet valves: the tables are as follows

\begin{tabular}{|c|c|c|c|c|}
\hline \multirow{2}{*}{ Type of Valve } & \multirow{2}{*}{ Parameter } & \multicolumn{3}{|c|}{ Lift } \\
\hline & & Low $(4.3 \mathrm{~mm})$ & Medium & High \\
\hline Base & \multirow{4}{*}{ Swirl Ratio } & 2.2500 & 0.9371 & 0.4840 \\
\hline 2 Mask & & 2.1600 & 1.0600 & 1.0300 \\
\hline 4 Mask & & 2.1300 & 1.0954 & 1.0445 \\
\hline 6 Mask & & 2.2945 & 1.0027 & 1.1858 \\
\hline
\end{tabular}

\begin{tabular}{|c|c|c|c|c|}
\hline \multirow{2}{*}{ Type of Valve } & \multirow{2}{*}{ Parameter } & \multicolumn{3}{|c|}{ Lift } \\
\hline & & Low $(4.3 \mathrm{~mm})$ & Medium & High \\
\hline Base & \multirow{4}{*}{ Swirl Ratio } & 2.2500 & 0.9371 & 0.4840 \\
\hline 2 Fins & & 2.7022 & 1.3334 & 0.6206 \\
\hline 3 Fins & & 2.5523 & 0.9832 & 0.6496 \\
\hline 5 Fins & & 2.5216 & 1.1215 & 0.7035 \\
\hline
\end{tabular}

\begin{tabular}{|c|c|c|c|c|}
\hline \multirow[b]{2}{*}{ Geometry } & \multirow[b]{2}{*}{ Parameter } & \multicolumn{3}{|c|}{ Lift } \\
\hline & & Low $(4.3 \mathrm{~mm})$ & Medium & High \\
\hline Base & \multirow{4}{*}{$\begin{array}{c}\text { TURBULENCE } \\
\mathrm{J} / \mathrm{KG}\end{array}$} & 9.2024 & 6.8722 & 7.4703 \\
\hline \multirow{3}{*}{ Type1 } & & 10.1236 & 8.8409 & 8.9454 \\
\hline & & 10.2076 & 8.4850 & 7.2898 \\
\hline & & 9.1038 & 8.3564 & 7.8411 \\
\hline & & & & \\
\hline \multirow[b]{2}{*}{ Geometry } & \multirow[b]{2}{*}{ Parameter } & \multicolumn{3}{|c|}{ Lift } \\
\hline & & Low $(4.3 \mathrm{~mm})$ & Medium & High \\
\hline Base & \multirow{3}{*}{$\begin{array}{c}\text { TURBULENCE } \\
\text { J/KG }\end{array}$} & 9.2024 & 6.8722 & 7.4703 \\
\hline \multirow{2}{*}{ Type2 } & & 8.4952 & 8.9541 & 7.5560 \\
\hline & & 8.8302 & 8.5638 & 7.7908 \\
\hline
\end{tabular}
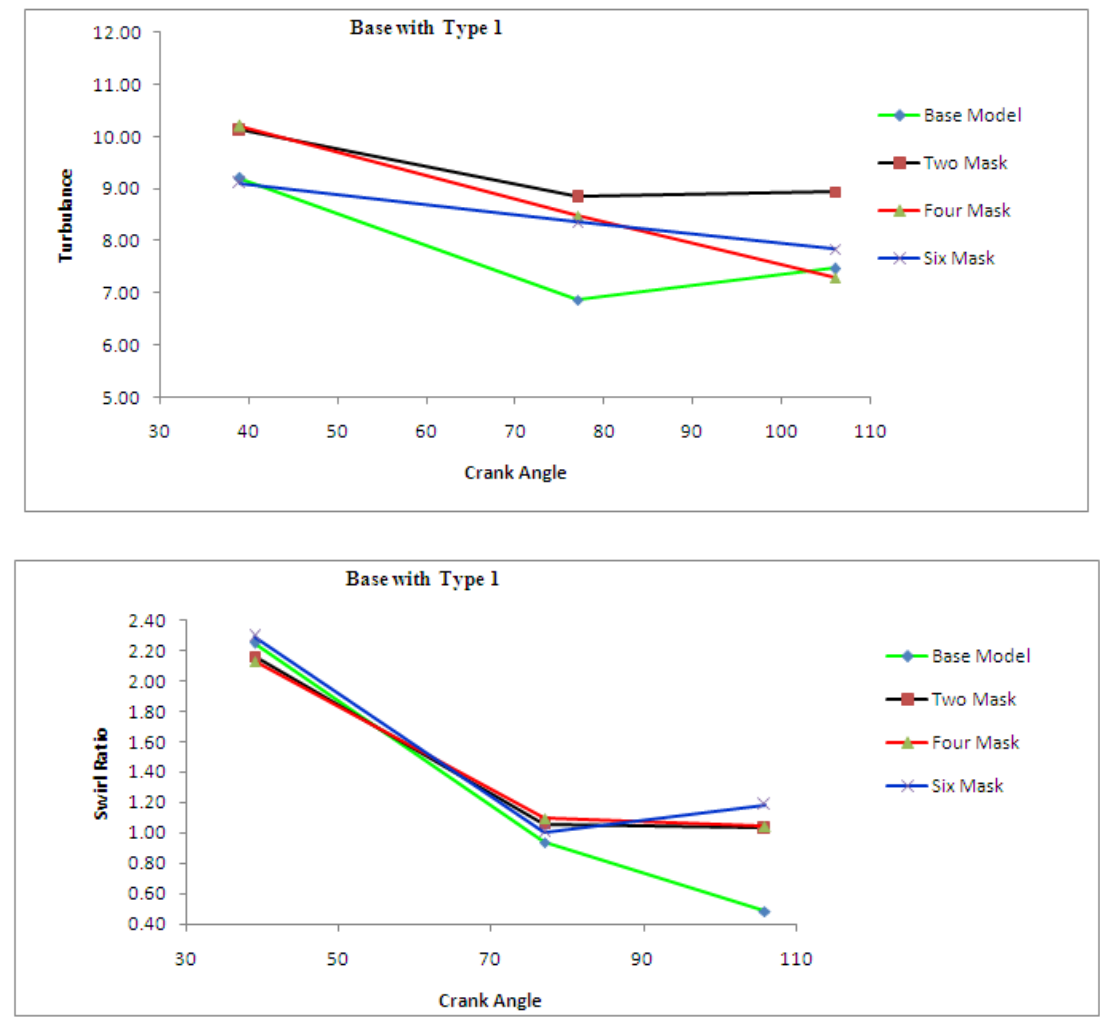
Here by observation of swirl and turbulent kinetic energy in above tables and graphs one can choose the best type of valve which will give optimum results among all varieties.

Hence we can go for 2 MASKED TYPE AND 3 FINNED TYPE INLET VALVES for physical models.

\section{Physical model preparation:}

1. Tungsten steel is selected for making fins and masks on the inlet valves because of;

2. It can with stand high temperature up to $800^{\circ} \mathrm{C}$ to $1000^{\circ} \mathrm{C}$.

3. It is wear resistant and has machine able properties.

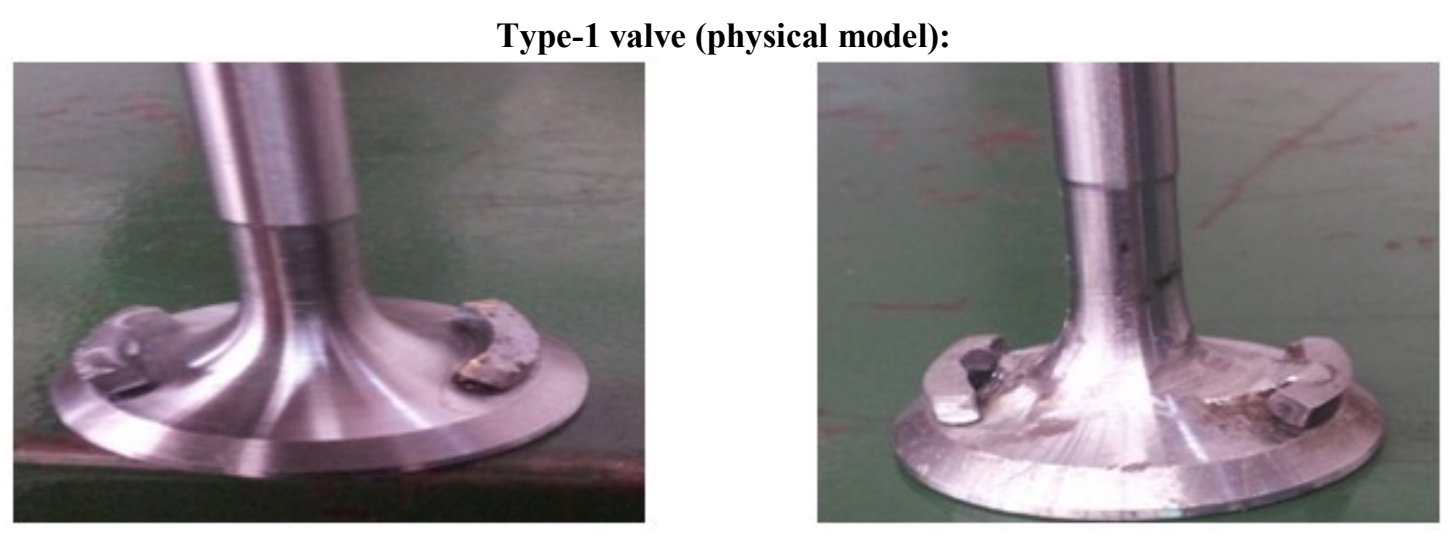

\section{Methodology}

1. Two pieces of tungsten in the shape of arcs with an angle $60^{\circ}$ are cut and finished in hand machines.

2. Arc pieces are welded with stainless steel welding electrode of $1.5 \mathrm{~mm}$ dia.

3. Special care is taken while positioning the masks on the valve as shown in the figure

4. Finally it is cooled in atmospheric temperature and finishing is done with small needle files and emery papers

5. Fins are also made by using lathe and drilling machines

6. Accurate size and shape of fins are made and finally finished with hand tools.

7. Fins are so smooth that it can rotate on valve head periphery when we blow air on to its vanes.

8. Engine head is well serviced and poppet valves are assembled with due care and tested for smooth and a foul free up and down movement of valves with a spring force.

9. Finally engine head is assembled with type- 1 valve and carried for experiment in lab.

10. Similarly the second type of valve is also assembled and tested in the same engine in the lab

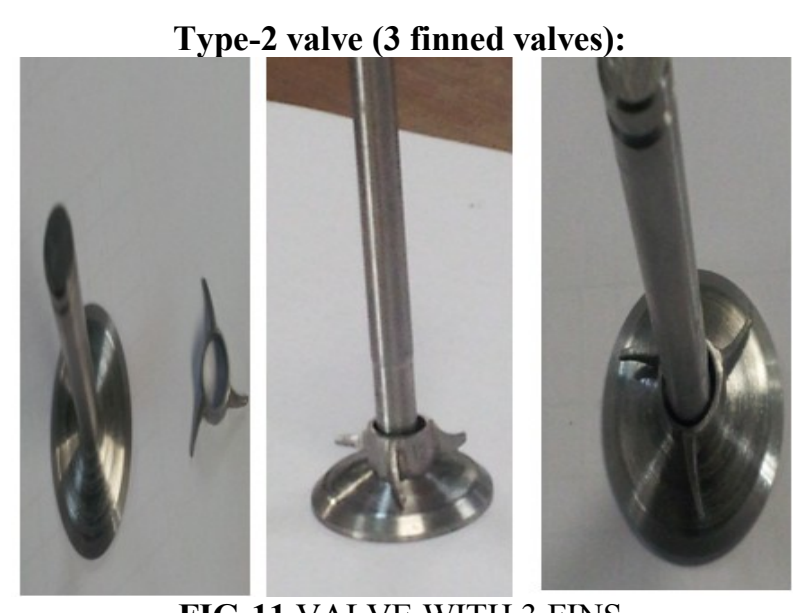

FIG-11 VALVE WITH 3 FINS 


\section{Experimental Set Up (Test Rig):}

Kirloskar Make Four Stroke Single Cylinder Diesel Engines Of Av Series.
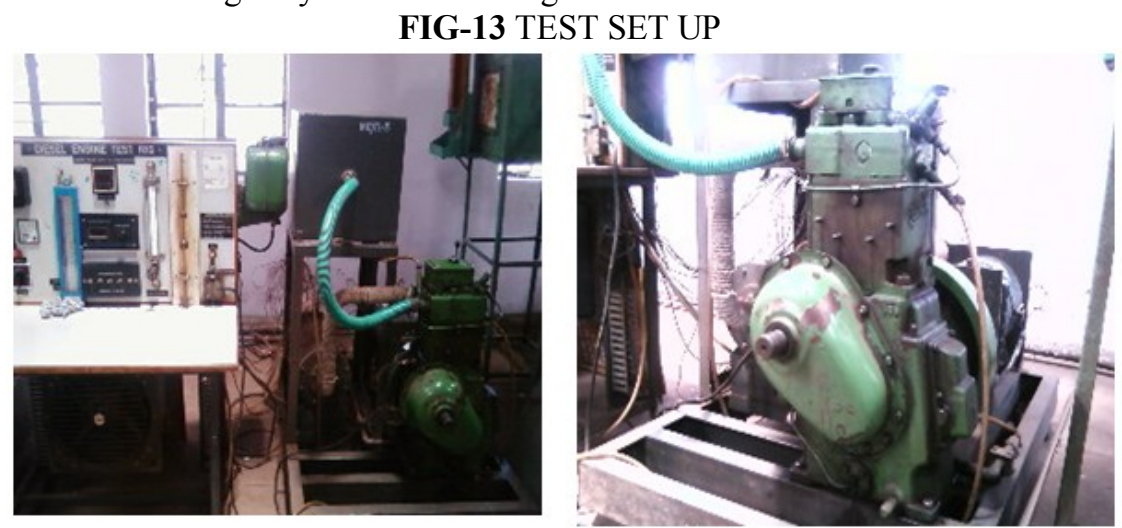

Test rig consists of:

1. Manometer to note down air head.

2. Water flow indicator

3. Burette to measure $10 \mathrm{cc}$ of oil consumed in 10 seconds

4. Thermo couple points to measure temperature of gases.

5. An electrical load starting from zero $\mathrm{kw}$ to $2.5 \mathrm{kw}$ load

6. A swinging arm field with spring force adjustment.

7. An orifice meter.

8. A crank handle to start engine

9. Initially load applied gradually from zero load to $2.5 \mathrm{~kW}$ and every reading is tabulated and calculations done by using specific formulae.

10

\begin{tabular}{|c|c|c|c|c|c|c|c|}
\hline NO & $\begin{array}{l}\text { TYPE OF } \\
\text { VALVE USED }\end{array}$ & $\begin{array}{c}\text { BRAKE } \\
\text { THERACAI } \\
\text { EFFICIENCY } \\
(\%)\end{array}$ & $\begin{array}{c}\text { DNDICAIFD TFRRNAII } \\
\text { EFFICIENCY } \\
(\%)\end{array}$ & $\begin{array}{c}\text { MECHANICAL } \\
\text { EFFICIENCY } \\
(\%)\end{array}$ & $\begin{array}{c}\mathrm{SFC} \\
\text { KGKW }\end{array}$ & $\begin{array}{l}c 0 \\
(\%)\end{array}$ & $\begin{array}{l}\mathrm{HC} \\
\mathrm{PPM}\end{array}$ \\
\hline 1 & BASE NODEL & 6 то 32 & 32 TO 45 & 18 TO 71 & 1.3700 .519 & 0.11 To 0.06 & 130 TO 80 \\
\hline 2 & $\begin{array}{l}2 \mathrm{NAASKED} \\
\text { VALVE }\end{array}$ & 6.15 to 38.15 & 32 TO 51 & 19 T0 75 & 12 To 0.49 & 0.1 To 0.02 & 120 TO 20 \\
\hline 3 & $\begin{array}{l}\text { 3FANNED } \\
\text { VALVE }\end{array}$ & 6.5 TO 36.16 & 35.5 TO 54.18 & 18 TO 72 & 1.22 TO 0.4 & 0.06 TO 0.03 & 70 TO 30 \\
\hline
\end{tabular}

Table-5

IV. Experimental Analysis:

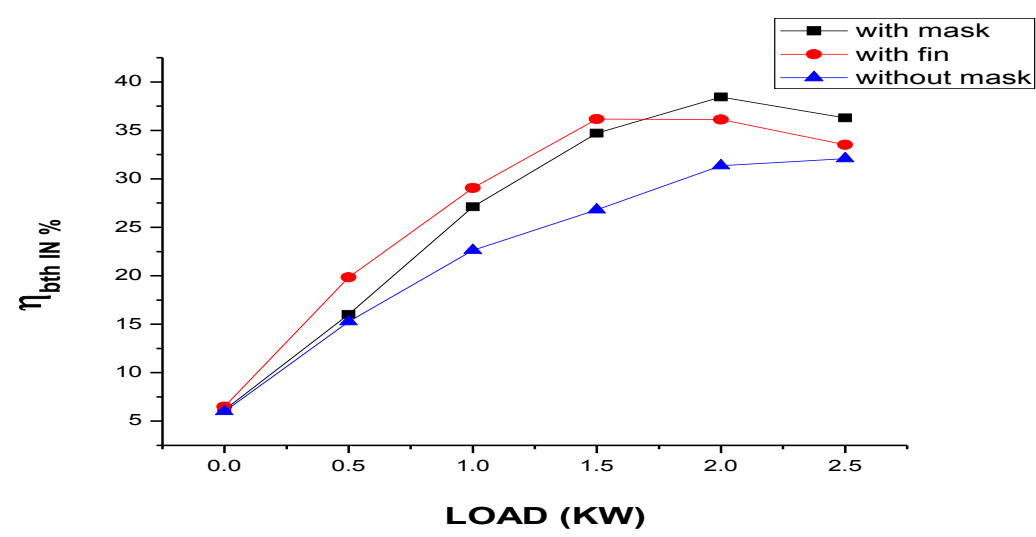

Fig-14 Brake Thermal Efficiecy Vs Load 


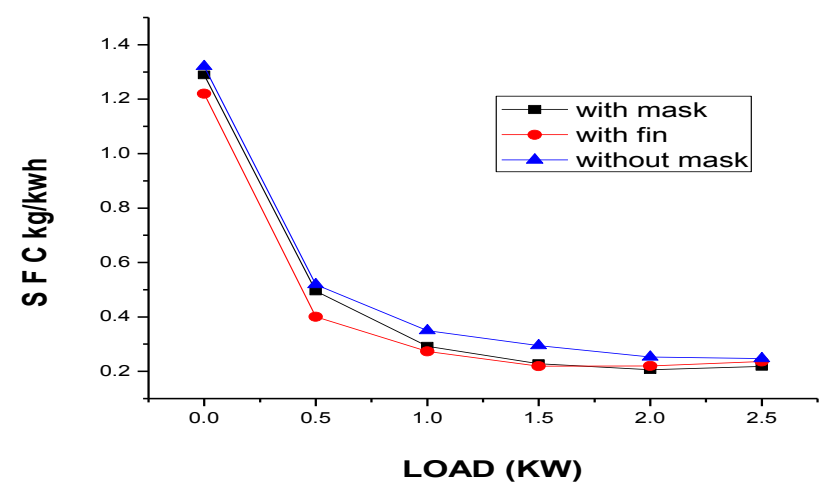

FIG-15 SFC Vs LOAD

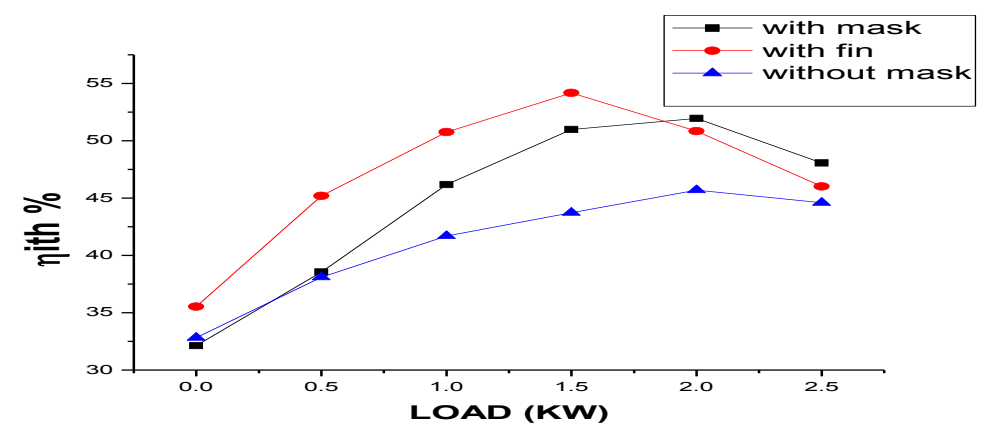

FIG-16 INDICATED THERMAL EFFICIENCY Vs LOAD

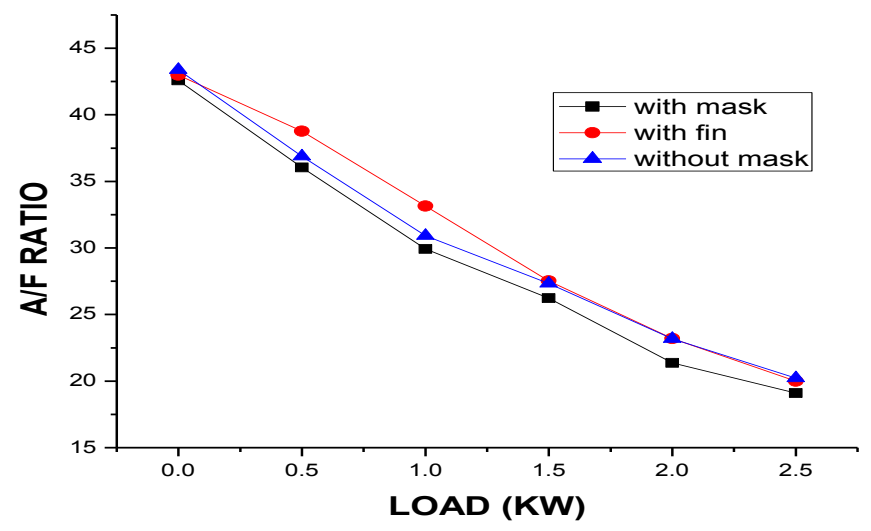

FIG-17 A/F Vs LOAD

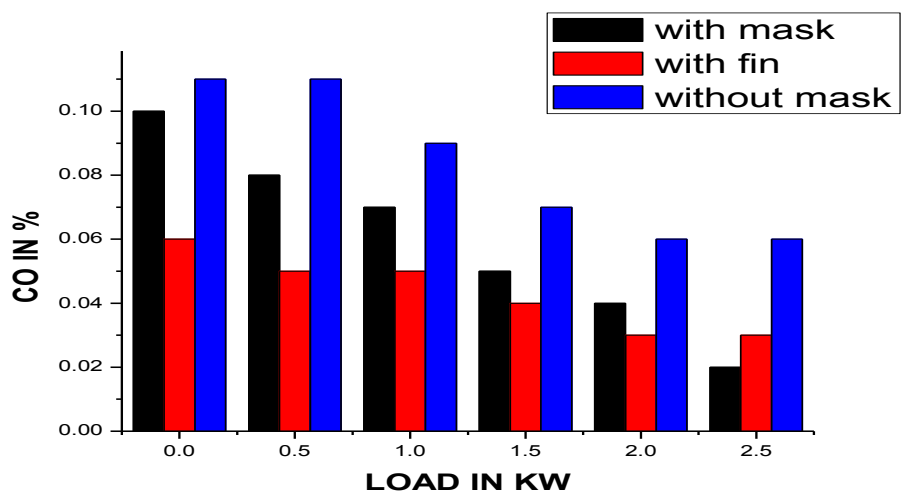

FIG-18 CO Vs LOAD 


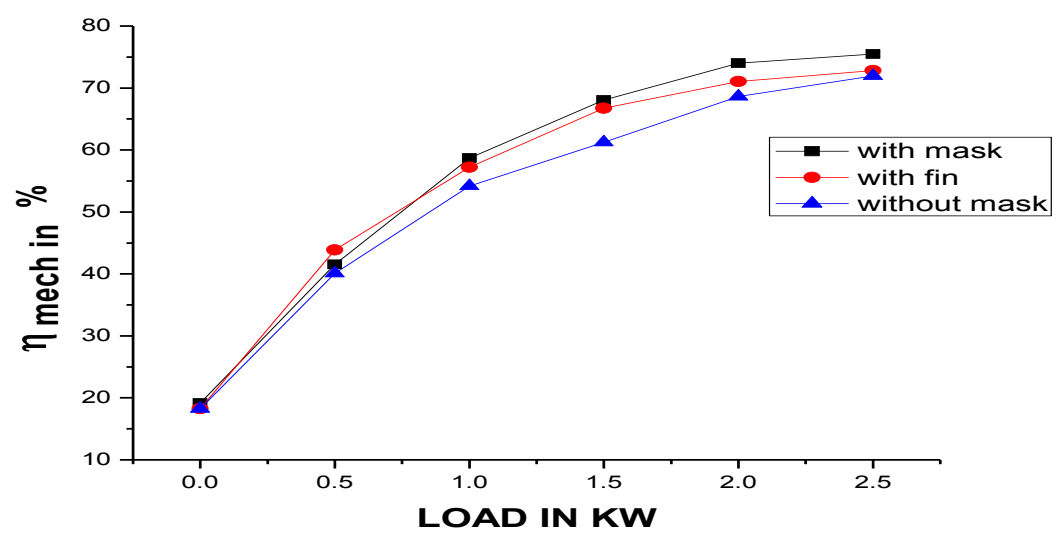

FIG-19MECH. EFFICIENCY Vs LOAD

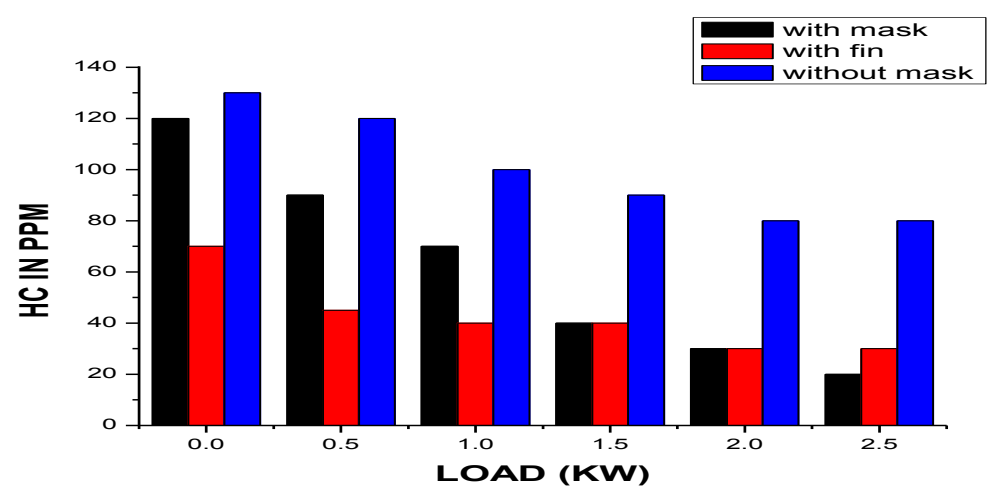

FIG-20HC Vs LOAD

\section{Conclusions}

1. Optimization of inlet air to the engine can be done by means of inlet poppet valves.

2. CFD simulation can advise better results.

3. Masking of inlet valves improves swirl rate and intern brake thermal efficiency of engine.

4. Fins also increase the swirl rate and hence we can get better thermal efficiency.

5. Pollution levels are also decreased with both valves when compared to conventional valve.

6. Manufacturing cost of masks and fins are less and can easily prepared

\section{Future Recommendations}

1. The shape of masks can be changed and to be checked.

2. The design and shape of fins can also be thoroughly studied.

3. The inlet valve rotation during process can be made static to enhance good swirl rates.

4. The engine valves can be modified to generate air swirl at the entrance for better performances.

5. Engine size can be made compact for same capacities with use of less air, i.e., with lower volumetric efficiencies and at high swirl rates for the same capacity, the engine can be made compact in size

\section{References}

[1]. Pandey K. M. and Roy Bidesh : Intake valve design for high level swirl Induction in carbureted spark ignition engine, Department of Mechanical Engineering, N.I.T Silchar, Assam (INDIA) JERDVol. 7 No. 1A, July-September 2012

[2]. Seita Akimoto Techniques for Low NOx Combustion on Medium Speed Diesel Engine TECHNICAL PAPER

[3]. Jorge MARTINS Design of an inlet track of a small i. C. Engine for swirl enhancement 20th International Congress of Mechanical Engineering Copyright (C) 2009 by ABCM November 15-20, 2009, Gramado, RS, Brazil

[4]. Bassem Ramadan, Study of swirl generation in di diesel engine using kiva-3v Kettering University

[5]. Christophe Garth Extraction and Visualization of Swirl and Tumble Motion from Engine Simulation Data, Univ. of Kaiserslautern (hagen@informatik.uni-kl.de)

[6]. Wendy Hardyono CFD Investigation of Fluid Flow and Turbulence Field Characteristics in a Four-Stroke Automotive Direct Injection Engine, University Kebangsaan Malaysia, 43600 UKM Bangi, Selangor Techniques for Low NOx Combustion on Medium Speed Diesel Engine

[7]. Fredrik Karlsson Modeling the Intake Manifold Dynamics in a Diesel Engine, Avdelning, Institution Division, Department

[8]. Abhilash M Bharadwaj Study of Swirl and Tumble Motion using CFD Research Scholar, Indian Institute of Science, Bangalore 
[9]. Mike Bergin Examination of initialization and geometric details on the results of cfd simulations of diesel engines International Multi-Dimensional Engine Modeler Meeting April 19, 2009, Detroit,

[10]. N. Neal and D. Rothamer an Optical Study of the Impact of Swirl Ratio on Extended Lift-off Diesel Combustion Spring Technical Meeting of the Central States Section of the Combustion Institute April 22-24, 2012

[11]. V.V. Prathibha Bharathi Influence of in cylinder air swirl on diesel engine performance and emission International Journal of Applied Engineering and Technology ISSN: 2277-212X (Online) 